Abstracta Iranica Abstracta Iranica

Revue bibliographique pour le domaine irano-aryen

Volume 28 | 2007

Comptes rendus des publications de 2005

\title{
«I due ambasciatori in Persia ricevuti da Papa Paolo V al Quirinale ». Miscellanea Bibliotecae Apostolicae Vaticanae, XII, 2005, pp. 357-425.
}

\section{Michele Bernardini}

\section{OpenEdition}

1 Journals

\section{Édition électronique}

URL : http://journals.openedition.org/abstractairanica/17981

DOI : 10.4000/abstractairanica. 17981

ISSN : 1961-960X

Éditeur :

CNRS (UMR 7528 Mondes iraniens et indiens), Éditions de l'IFRI

\section{Édition imprimée}

Date de publication : 15 mai 2007

ISSN : 0240-8910

Référence électronique

Michele Bernardini, « «I due ambasciatori in Persia ricevuti da Papa Paolo V al Quirinale ». Miscellanea Bibliotecae Apostolicae Vaticanae, XII, 2005, pp. 357-425. », Abstracta Iranica [En ligne], Volume 28 | 2007, document 191, mis en ligne le 18 septembre 2007, consulté le 25 septembre 2020. URL : http:// journals.openedition.org/abstractairanica/17981 ; DOI : https://doi.org/10.4000/abstractairanica. 17981

Ce document a été généré automatiquement le 25 septembre 2020.

Tous droits réservés 


\title{
«I due ambasciatori in Persia
} ricevuti da Papa Paolo V al Quirinale ». Miscellanea Bibliotecae Apostolicae Vaticanae, XII, 2005, pp. 357-425.

\author{
Michele Bernardini
}

1 Après une introduction historique sur les relations entre la Papauté et l'Iran depuis la conquête mongole jusqu'au XVI ${ }^{\mathrm{e}}$ s., l'A. décrit la personnalité d'Ippolito Aldobrandini, Pape Clément VIII (1592-1605), qui conjugua l'encouragement de l'activité missionnaire à l'ardeur anti-ottomane. Ce dernier élément, impliquant un accord international, intéressa fortement la Perse, à l'époque gouvernée par Šāh 'Abbās I $\mathrm{I}^{\text {er }}$ (1587-1629). Les Safavides désiraient en effet parvenir à l'élimination de la colonie portugaise d'Hormuz, d'un côté, et contenir les Ottomans, de l'autre côté. À son tour, le Pape semble avoir espéré une conversion du Shah, puisqu'il envoya deux Portugais, Francesco da Costa (un ex-jésuite, originaire de Goa) et Diego de Miranda. Les instructions que ceux-ci reçoivent mentionnent le culte des saints persans dans l'église de Rome (comme l'ajoute Piemontese, l'Église célèbre pour l'occasion «la Perse paleo-chrétienne à Rome »). En 1599, en réponse à cette ambassade, où l'origine portugaise des deux envoyés constitua d'ailleurs un grand handicap, 'Abbās $\mathrm{I}^{\mathrm{er}}$ envoya une grande ambassade en Europe destinée à se rendre à Rome, Prague et Valladolid. Cette ambassade, la plus célèbre des ambassades safavides, était co-dirigée par Hoseyn 'Alī Beg Bayāt et Anthony Sherley, conseiller militaire anglais à la cour safavide. L'accueil de cette ambassade à Rome fut somptueux (5.IV.1601), mais son déroulement ne manqua pas de complications. En fait, le frère de Sherley, Robert, expert en artillerie, était resté " presque un otage » en Iran pour aider 'Abbās I ${ }^{\text {er }}$ à chasser les Portugais de Hormuz, ce qui n'arriva qu'en 1622. Antony Sherley et Bayāt partiront vers l'Espagne, tandis que trois membres safavides de l'ambassade - un secrétaire, un barbier et un cuisinier - se convertiront au christianisme à Rome. C'est le Pape lui-même qui les 
baptisa, en compagnie de neuf Juifs et d'un Turc, à la Basilique de Saint-Jean-de-Latran (29.VIII.1601).

2 D'autres ambassades suivent celle de Bayāt et Sherley. À l'époque de Camillo Borghese (Paul V, 1605-1621), une mission part pour l'Iran; elle se révèlera très importante non seulement pour les dénouements politiques, mais surtout culturels qu'elle apportera. En 1606, Giovan Battista Vecchietti avait envoyé d'Eșfahān un projet pour la traduction en persan de la Bible. Bien que ce projet n'eût pas de succès, la mission diplomatique en Iran menée par Paolo Simone di Gesù Maria O.C.D. rejoignit Eșfahān à la fin de 1607 et, déjà au début de l'année suivante, elle obtient les lettres de 'Abbās I ${ }^{\mathrm{er}}$ destinées au Pape Paul V et au roi d'Espagne Philippe III. C'est à ce moment-là que réapparaît Robert Sherley; ayant entre-temps épousé une Circassienne, sa lune de miel est interrompue par le Shah qui le mande à la cour pour l'envoyer en Europe via la Moscovie, la Pologne et l'Allemagne.

3 L'étude de Piemontese est enrichie par différents documents ajoutés en fin d'article se rapportant aux deux ambassades. L'A. attire aussi l'attention sur l'importance d'un considérable répertoire iconographique qui reproduit les évènements. Il s'agit avant tout de nombreuses gravures, mais également de fresques. L'une de ces fresques, réalisée par Agostino Tassi et Carlo Saraceni, est parfaitement conservée encore aujourd'hui sur les murs de la "Sala Regia » du palais du Quirinale à Rome. Datant de 1616-1617, elle représente la série des ambassades étrangères préférées de Paul V : Congo (1608), Perse (1609) et Japon (1615). L'article se termine avec un appendice contenant les traductions latines des lettres d"Abbās $\mathrm{I}^{\mathrm{er}}$ au Pape Paul V.

INDEX

Thèmes : 4.2.1. Safavides et Qâjârs

\section{AUTEURS}

MICHELE BERNARDINI

Università di Napoli « L'Orientale » 